\title{
Gestos de interpretação em favor de uma leitura múltipla
}

\section{Interpretation gestures in favor of a multiple reading}

https://doi.org/10.34112/2317-0972a2016v34n66p47-59

Wagner ERnesto Jonas Franco ${ }^{1}$

ResUMO: O objetivo deste trabalho é compreender os gestos de leitura e interpretação de que o sujeito-aluno lança mão diante do texto e a forma como se constitui autor a partir deles. Para isso, analisar-se-á a descrição escrita de uma tirinha em quadrinhos lida pelos alunos em uma oficina de escrita na escola em que estudam em Pouso Alegre-MG. A base teórico-metodológica é a Análise de Discurso de linha francesa. Com esse estudo concluiu-se que é constitutivo do sujeito o caráter heterogêneo da língua: os alunos possuem diferentes relações com a língua(gem), e o trabalho com textos autênticos, relevantes e valorizados socialmente pode contribuir para melhorar a leitura escolar e o posicionamento como autor do que escreve.

Palavras-chave: Gestos de leitura; sujeito; texto; linguagem.

ABSTRACT: The objective of this work is to analyze the student's gestures of reading and interpreting while working on the text and the authorship features of these gestures. In order to do so, we have analyzed the written description of a comic strip read by students during a writing workshop class organized by the school where they study in Pouso Alegre, in the state of Minas Gerais. The theoretical and methodological basis is the French Discourse Analysis. Based on this study, we have concluded that the heterogeneous character of the

1. Secretaria Municipal de Educação de Pouso Alegre, Pouso Alegre, MG, Brasil. 
language is constitutive of the subject: the students show different relationships with the language and the work with relevant, authentic and socially valued written material can help to improve school reading and serve as a tool for authorship when one writes.

Keywords: Gestures of reading; subject; text; language.

\section{INTRODUÇÃO}

Repara bem no que não digo.

(Paulo Leminski)

Quando se trata de leitura e escrita, alguns equívocos estão tradicionalmente presentes na escola contemporânea. Para citar alguns, temos: a relação instrumental com a língua por parte de professores e alunos, a ilusão da transparência da linguagem, a não opacidade do texto e uma relação de completude com uma língua entendida em si mesma, que exclui o sujeito falante em favor de uma metalinguagem nas aulas de línguas e redação.

Dentre os problemas levantados, o objetivo deste trabalho é compreender os gestos de leitura e interpretação de que o sujeito-aluno lança mão diante do texto e o modo como ele se constitui autor a partir desses gestos. Para isso, analisaremos a descrição por escrito de um texto (tirinha em quadrinhos) lido pelos alunos em uma aula de uma oficina de escrita promovida pela escola em que eles estudam.

Embasada em Orlandi (2008, p. 90), que afirma: "A leitura é um dos elementos que constituem o processo de produção da escrita.", nossa hipótese é a de que a constituição do sujeito-aluno como autor se inicia no seu gesto de interpretação do texto. Se a escola compreende o texto como um veículo de informação com sentido único, a assunção da autoria do aluno estará prejudicada, já que, de acordo com Orlandi (2008), a função autor é aquela mais próxima do social, responsável pela coesão e pela coerência do texto, levando-se em conta o interlocutor. Mas, se a escola compreende e trabalha o caráter prático e social da língua e o texto como “peça de linguagem” (ORLANDI, 2007), a função autor do aluno será facilitada.

Este trabalho se justifica pela relevância de discutir aspectos da leitura e da escrita escolar, pois em relação a esses assuntos ainda há muito que melhorar. A divisão social da leitura já foi discutida por Pêcheux em "Ler o arquivo hoje" (2010). Nesse texto, Pêcheux denuncia como certos grupos tentam transmitir um sentido único ao texto. Para a Análise de Discurso, a leitura é múltipla, pois diferentes discursos 
atravessam o texto e os sujeitos-leitores. Acreditamos que problematizar a leitura, desmistificando o sentido único da leitura, traz contribuições para a escola, para a universidade em seu caráter científico e para a sociedade em geral.

A proposta de UMa leitura múltipla em UMA Oficina de leitura E ESCRITA

A leitura escolar passa primeiramente pela compreensão que a escola tem de língua. É comum nas aulas de Língua Portuguesa a fragmentação da língua e seu ensino em uma escala de dificuldade em que prevalece uma metalinguagem que exclui o sujeito. A consequência é compreender o texto como uma reunião de sentenças cujo sentido se encerra nele mesmo. A compreensão de texto também é um aspecto importante para a leitura, a ser trabalhado na escola. Orlandi (2007) diz que o texto é um objeto com começo, meio e fim e não é uma unidade fechada. "Um texto tem relação com outros textos, com suas condições de produção, com o que chamamos sua exterioridade constitutiva." (ORLANDI, 2007, p. 54).

Além disso, Orlandi (2007) afirma que o texto é materialidade histórica. Há uma historicidade inscrita nele. Por historicidade, devemos entender os sentidos inscritos no texto e não um reflexo da história no texto, pois não se trata de "conteúdos" prontos existentes e, sim, uma construção de sentidos a partir do texto. Em uma palavra, a leitura é historicidade, pois traz o sujeito (leitor, escritor) de volta à língua. A historicidade compreende que os processos de significação são determinados pelas condições de produção dos sentidos - os sujeitos e a situação - sustentados pelas posições que esses sujeitos ocupam na sociedade. A leitura é produzida (ORLANDI, 2008).

O que se percebe na escola hoje em dia é que há uma desconsideração dos aspectos históricos da constituição dos sentidos, em nome de um sentido único institucionalizado. Orlandi (2008) afirma que a leitura considerada correta é aquela que a classe média faz. A escola nega que o sentido (sempre) pode ser outro. Mariani (2003) complementa, ao dizer que a relação escola-aluno é estranha à história do aluno: "Há uma barreira histórico-social e linguageira no ler/escrever na instituição escolar que não pode ser reduzida ao desconhecimento do dialeto padrão, como muitos afirmam. Nessa 'barreira de linguagem' existente está inscrita uma 'barreira ideológica”" (MARIANI, 2003, p. 106). 
Portanto, trabalhar a historicidade na/da leitura parece ser um caminho a trilhar pela escola. Para a língua significar, é preciso que a história intervenha. Uma história feita por sujeitos em um ambiente social. A leitura é, então, interação entre sujeitos: "O leitor não interage com o texto (relação sujeito/objeto), mas com outro(s) sujeitos(s) (leitor virtual, autor etc.)” (ORLANDI, 2008, p. 9).

$O$ processo de significação do texto se desencadeia com os interlocutores, ou seja, quando o sujeito-escritor escreve sabendo que seu texto será lido. Para isso, o sujeito-escritor precisa se fazer entender para/pelo outro (o interlocutor), principalmente, e não apenas para si mesmo. Em outras palavras, é o que Orlandi (2008) diz do confronto entre o leitor virtual (constituído no ato de escrita) e o leitor real (aquele que de fato lê o texto). Escrever e ler envolve responsabilidades por parte tanto de quem escreve quanto de quem lê.

O problema que a escola apresenta, a nosso ver, é a falta de um interlocutor nas atividades de escrita, para caracterizar seu aspecto social, e a falta de um trabalho com a responsabilidade na escrita. Na escola, escreve-se, muitas vezes, apenas para outros alunos ou para o próprio professor, e este se preocupa apenas com a metalinguagem inscrita nos textos, uma correção de aspectos gramaticais. A escola precisa propor formas de inserir o interlocutor em suas atividades de escrita.

Fundamentados pela Análise de Discurso e suas compreensões de língua, texto, leitura e escrita tratadas até aqui, estudantes e professores do Programa de PósGraduação em Ciências da Linguagem de uma universidade particular no sul de Minas firmaram uma parceria com uma escola também particular e realizaram oficinas de leitura e escrita no ano de 2014, para propor uma nova compreensão sobre leitura e escrita. $\mathrm{O}$ objetivo das oficinas era sanar eventuais dificuldades dos alunos em relação à escrita e à leitura. A própria escola escolhia alunos com suposta dificuldade para participar das oficinas. Foram agendados com os alunos encontros quinzenais onde acontecia a leitura e a discussão de textos variados sobre um determinado tema escolhido previamente entre os pesquisadores. Este trabalho pauta-se no segundo encontro da oficina. Participaram seis alunos (cinco meninas e um menino, entre 14 e 15 anos) do nono ano do ensino fundamental. Após a apresentação do tema "Sentimentos de Perda" e a discussão de algumas tirinhas relacionadas a ele, os professores-pesquisadores solicitaram que os alunos descrevessem por escrito a seguinte tirinha: 

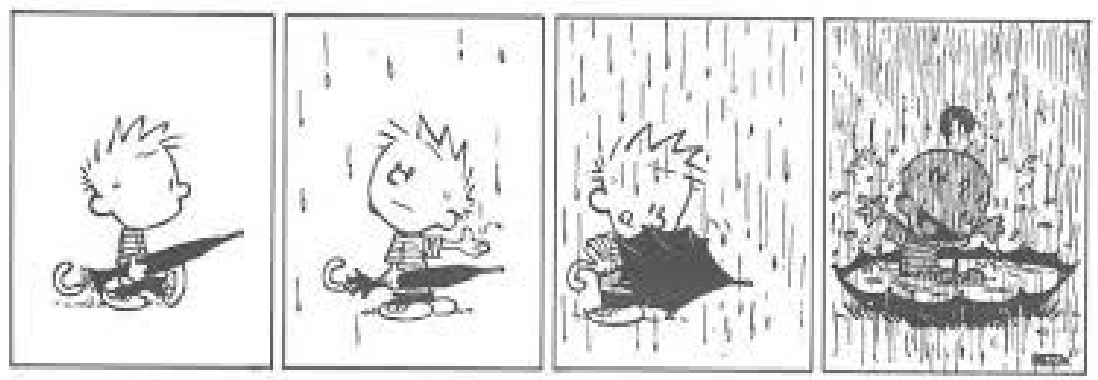

Figura 1 - Tirinha do personagem Calvin. Fonte: www.gocomics.com

Sobre o tema introdutório "Sentimentos de Perda", os pós-graduandos, inclusive este pesquisador, discutiram perdas que os alunos porventura tivessem enfrentado ao longo da vida, seja de um ente querido, um animal de estimação, uma oportunidade, um(a) namorado(a) etc. A proposta de escrita não era em torno desse tema, mas da tirinha acima. Por questão de espaço, das seis composições escritas, escolhemos as quatro mais curtas para compor nosso corpus.

\section{LEITURA, INTERPRETAÇÃo E AUTORIA A PARTIR DA TIRINHA}

As tirinhas em quadrinhos em geral apresentam um tema corriqueiro com um efeito cômico ao final; via de regra esse efeito se dá pela quebra da expectativa do leitor: algo inesperado acontece, diferente do que foi levado a crer no início da leitura. A tirinha apresentada é composta apenas de linguagem não verbal, sem falas: o personagem principal, Calvin, aparece no primeiro quadrinho andando com um guarda-chuva na mão; no segundo quadrinho, percebe que vai chover; no terceiro quadrinho, inicia um movimento para abrir o guarda-chuva; e no quarto quadrinho - a quebra da expectativa do leitor -, em vez de se proteger da chuva, Calvin brinca nela dentro de seu guarda-chuva em forma de piscina. Na própria constituição do texto, percebe-se a abertura do simbólico: Calvin faz do guarda-chuva um brinquedo, condizente com sua idade de 6 anos. E a chuva, que seria um incômodo para um adulto, é motivo de felicidade para Calvin.

A análise será feita de acordo com a proposta de Orlandi $(2007,2008)$ sobre sujeito e autoria. Procuraremos perceber, na heterogeneidade do universo discursivo, as marcas da inserção da autoria do sujeito-aluno enquanto leitor e escritor. Mostraremos as multiplicidades de sentidos atribuídos ao mesmo objeto simbólico. 
Para isso, trazemos a compreensão de interpretação, ideologia e formações imaginárias.

A interpretação tem relação com a ideologia. Face a qualquer objeto simbólico, o sujeito é obrigado a interpretar (ORLANDI, 2006). Interpretar é significar, "tornar possíveis gestos de interpretação" (ORLANDI, 2006, p. 24). O sujeito interpreta a partir de uma condição de produção específica. Mas o sujeito tem a impressão de que sua interpretação é única e verdadeira. Essa impressão é dada pela ideologia. A ideologia é a evidência de um sentido sempre-já-lá.

O processo ideológico sustenta-se sobre um já-dito. Os sentidos aparecem como naturais e universais. A ideologia apaga a interpretação no momento em que ela acontece. Os sentidos apresentam-se para o sujeito como que colados às palavras. Mas os sentidos se inserem em formações discursivas, que, em uma conjuntura sócio-histórica dada, definem o que pode e deve ser dito.

Agora, dentro das condições de produção dos sentidos, temos o mecanismo de antecipação. Segundo ele, o sujeito assume a posição de seu interlocutor como que para antecipar o efeito de sentido provocado por seu dizer. A antecipação liga-se à formação imaginária. Em Análise de Discurso, a compreensão do sujeito não é a de um sujeito físico, empírico, sociológico, que existe a priori, mas de um sujeito que se constrói no discurso. Os sujeitos assumem uma posição-sujeito. O que conta são as imagens que os sujeitos produzem de si mesmos e dos seus interlocutores. As situações de fala serão regidas por essas imagens.

Ainda é comum na cultura ocidental a imagem de um sujeito único, natural, logocêntrico, origem e fonte de seu dizer, com uma identidade una e pronta. No âmbito da aprendizagem, esse sujeito é o da memória cognitiva, que está na escola para aprender vocabulário, estruturas, sentenças prontas, a verdade única do professor. Para a Análise de Discurso, a identidade é sempre móvel, está em constante transformação; o sujeito é constitutivamente heterogêneo, ele assume diversas posições em diferentes situações - ao dizer, ele retoma sentidos preexistentes. A partir desse sujeito da Análise de Discurso é que compreenderemos nosso corpus.

O SUjeito-leitor escolar e a AUtoria NA ANÁlise do CORPUS

Empreenderemos a análise com base na proposta inicial das oficinas/encontros de escrita de trabalhar com a incompletude da língua, com sua tendência constitutiva à falha e ao equívoco, bem como com a compreensão de um sujeito dividido 
e falho. Como pode ser analisado nos recortes, orientar-nos-emos pelas perguntas de pesquisa: Como/quais gestos de interpretação empreendidos pelos alunos colaboram para a assunção de sua autoria? E esses gestos de interpretação apreendem na tirinha a quebra da expectativa do leitor? O propósito é verificar os efeitos de sentido que as leituras das oficinas provocaram nos alunos e em que medida os encontros podem ser melhorados.

Para Orlandi (2008), o autor é uma das representações do sujeito. Não há um autor intrínseco no indivíduo. Há uma função-autor que deve ser trabalhada, principalmente na escola. A autora, a partir de Ducrot (1985), diferencia o autor do locutor e do enunciador. O locutor é aquele que se representa como eu no discurso; o enunciador é a perspectiva que esse eu constrói. $\mathrm{O}$ autor é a função que nos interessa aqui. Orlandi (2008, p. 77-80) diz:

O autor está na base da coerência do discurso. [...] está mais afetado pelo contato social e suas coerções. [...] (é) a dimensão do sujeito que está mais determinada pela exterioridade (contexto sócio-histórico), ela está mais submetida às regras das instituições. [...] A responsabilidade do autor é cobrada em várias dimensões: quanto à unidade do texto, quanto à clareza, quanto à não-contradição, quanto à correção etc. exige-se uma relação institucional com a linguagem.

Procuraremos perceber se ocorrem, na escrita dos textos dos alunos, as características acima mencionadas, com o objetivo de verificar se há, de fato, "assunção da autoria" por parte deles. Segue o primeiro recorte ${ }^{2}$ :

$\left[\mathrm{RD}_{1}\right]^{3}$ : Calvin sai com um guarda-chuva / percebe que está chovendo / ele abre o guarda-chuva.../ para fazer uma piscina

Uma avaliação rápida e ingênua deste primeiro recorte julgá-lo-ia como curto, desestruturado (uma frase embaixo da outra em vez de parágrafos) e mal pontuado. No entanto, ao compreender o texto como materialidade de discursos e discurso como efeito de sentido entre locutores, percebe-se que o aluno Pedro ${ }^{4}$ escreve quatro frases, uma para cada quadrinho da tirinha. Seu gesto de interpretação atribui

2. Os recortes serão transcritos o mais fielmente possível, inclusive com todos os desvios de ordem gramatical.

3. Recortes discursivos

4. Os nomes dos alunos serão fictícios para preservar suas identidades. 
sentido coerente à tirinha. A coerência, segundo o dicionário Aurélio (FERREIRA, 2005, p. 243), é "harmonia entre idéias, ou acontecimentos". Percebe-se também um interlocutor em seu texto.

Ele inicia o texto com o personagem principal da história, "Calvin", para situar o leitor/interlocutor em sua leitura. Como essa é a primeira referência ao personagem, seu nome não gera dúvidas sobre de quem trata o texto. Na segunda frase, o aluno evita a repetição do sujeito e opta por uma elipse, sujeito oculto. Em seguida, na terceira frase, insere um pronome da terceira pessoa para retomar o sujeito, dar clareza e unidade ao texto. A quarta frase completa gramaticalmente a terceira. Nesta última frase, o aluno fecha o texto com unidade e coerência. Ao dizer "para fazer uma piscina", ele traduz a quebra da expectativa na tirinha, o guarda-chuva muda de significação: vira um brinquedo coerente com a idade do personagem. $\mathrm{O}$ aluno poderia ter encerrado com a (pará)frase: "Calvin ficara dentro do guarda-chuva cheio de água”, mas não traria os mesmos sentidos. Não haveria a compreensão da relação que guarda-chuva, chuva e piscina mantêm com brinquedo.

Fato que chama a atenção refere-se às reticências que o aluno insere ao final da terceira frase. Segundo Faraco e Moura (1994, p. 371), "as reticências (podem) indicar interrupção da fala do narrador ou da personagem". Essa interrupção marca a abertura do simbólico. É a interpretação do aluno que marca um "vestígio do possível”. Em Análise de Discurso, compreende-se que o sujeito não precisa dizer para significar, o silêncio também significa. Essas reticências são marcas do silêncio, elas não dizem, mas significam. Cabe ao leitor recuperar essa significação, pois ele também tem responsabilidade ao ler, o que Orlandi (2008) chama de "efeito-leitor". Depreende-se que, tendo um imaginário de leitor para seu texto, houve uma assunção de autoria por parte do aluno. A responsabilidade social na construção do texto foi alcançada.

O segundo recorte vai ao encontro do primeiro. Eles mantêm uma mesma ideia. Podemos dizer que pertencem a uma mesma formação discursiva. $O$ texto é mais elaborado, apresenta oito linhas e é estruturado em dois parágrafos. A aluna demonstra uma familiaridade maior com textos. Há elementos presentes em outros discursos, como os textos narrativos. Segue o recorte:

$\left[\mathrm{RD}_{2}\right]$ : Calvin acaba de sair de casa com um guarda-chuva preto na mão. De repente ele percebe que começa a chover, mas isso não é problema, pois ele tem um guarda-chuva. Calvin abre o guarda-chuva rapidamente e quando você espera que ele vai usa-lo para não se molhar; ele vira o guarda-chuva de cabeça para baixo e o faz como uma piscina 
Da mesma forma que o primeiro aluno, a aluna inicia o texto situando o leitor/ interlocutor quanto ao personagem principal da história. No restante do parágrafo, ela retoma o personagem pelo pronome da terceira pessoa "ele", para evitar a repetição. No segundo parágrafo, ela repete esse procedimento. Essa retomada garante unidade e coesão ao texto. A aluna também usa conectivos como "de repente", "isso", "pois", "mas", "e", "o", entre outros, para ligar termos e orações e dar harmonia ao texto.

A quebra da expectativa se dá quando ela introduz a oração: "ele percebe que vai chover, mas isso não é problema": o pronome demonstrativo "isso" retoma chuva, que não é problema para Calvin. E o aspecto interlocucional é reforçado com a frase "quando você espera que ele vai usá-lo para não se molhar...", em que "você" é para quem ela escreve o texto. Novamente, tem-se aqui uma assunção de autoria alcançada pelo aluno.

O terceiro recorte apresenta efeitos de sentido congruentes com os dois acima analisados. Ele é um exemplo de como a língua, enquanto base material de discursos e sujeita a falhas, é compreendida neste trabalho:

[RD 3 : Calvin saiu de casa procurando chuva, / então começou a chover, porem / a chuva foi aumentando e o guar- / da-chuva foi usado como piscina / pois já estava cheio de água

Neste terceiro recorte, a opacidade semântica da palavra "procurando", na primeira frase, chama a atenção. A palavra leva à pergunta: quem sai de casa para procurar chuva? Se procura, para quê? Recorremos a Orlandi (2008, p. 103) para ajudar a elucidar essas questões:

Na produção da linguagem, o que temos não é transmissão de informação mas efeito de sentido entre locutores (Pêcheux, 1969). Daí decorre o que se pode chamar de "efeito-leitor". A noção de efeito supõe, entre outras coisas, a relação de interlocução na construção de sentidos. Sem esquecer que os sentidos não são propriedades privadas: nem do autor, nem do leitor. Tampouco derivam da intensão e consciência dos interlocutores. São efeitos da troca de linguagem. Que não nascem nem se extinguem no momento em que se fala.

Percebemos, então, que, ao inserir a palavra "procurando", a aluna faz um gesto de interpretação coerente com a tirinha, para significar em seu texto a relação que 
Calvin, uma criança de 6 anos, mantém com a chuva e o guarda-chuva. A chuva não significa apenas chuva na tirinha. A aluna apreende o que a chuva significa para Calvin e insere em seu texto para reproduzir esse sentido para o interlocutor. Pelo mecanismo de antecipação, ela se posiciona como o leitor de seu texto e prevê efeitos de sentidos possíveis que a palavra "procurando" pode causar.

Em relação à coesão, a aluna conecta as cinco frases de seu texto com os conectivos "então", "porém", "e" e "pois". Mas o conectivo "porém", enquanto conjunção adversativa que estabelece uma relação de oposição entre duas orações (FARACO; MOURA, 1994), não estabelece essa relação com a frase seguinte, já que Calvin está "procurando chuva", portanto querendo que ela aconteça. No entanto, se pensarmos a língua e o sujeito enquanto sujeitos à falha, ao equívoco e à incompletude $\mathrm{e}$ se ponderarmos que não há relação direta entre linguagem, pensamento e mundo, podemos chegar à seguinte paráfrase do texto da aluna: "Calvin saiu de casa procurando chuva. Então, começou a chover. A chuva foi aumentando, porém o guarda-chuva foi usado como piscina, pois já estava cheio de água..”

A paráfrase acima evidencia que algo escapa ao controle gramatical. "A palavra não vai em todos os sentidos" (MILNER, 2012, p. 7). Milner (2012, p. 33) diz que os gramáticos são defensores de um real que é representável na língua, ao que ele se opõe: "o real não é representável, matematizável".

\section{Próximo recorte:}

[RD4]: Calvin sai andando com um / guarda-chuva. / Coloca a mão para sentir a / chuva / Com alguma idéia na / cabeça, abre o guarda chuva. / A idéia não era se proteger / da chuva e sim saborear. / "Nadando" no guarda chuva

Neste recorte o que chama a atenção são os efeitos de sentido que os verbos sensoriais provocam. Provavelmente, foram utilizados para traduzir a relação de Calvin com a chuva. O verbo "sentir" relaciona-se ao tato: "coloca a mão para sentir a chuva", e o verbo "saborear" relaciona-se ao paladar. Esses efeitos de sentido remetem a uma formação discursiva ligada à infância, em que a criança (Calvin?) tem um contato físico-corporal com qualquer coisa que encontre pela primeira vez.

A palavra "nadando", que também envolve o corpo, está entre aspas. O que há é um deslocamento de sentido da palavra "nadar", usualmente pertencente a uma formação discursiva que envolve a natação enquanto esporte. Há aqui um entrecruzamento de discursos e um efeito metafórico. Que é a deriva de sentidos 
possíveis, deslizamento (PÊCHEUX, 1990). A palavra refere-se a algo mais que simplesmente nadar. Em uma relação parafrástica, "nadando" tem o sentido de "brincando".

Em relação à quebra da expectativa, pode-se atentar para a frase "com alguma ideia na cabeça": o pronome indefinido "alguma" deixa para o leitor a apreensão dos sentidos possíveis, essa "ideia" na cabeça de Calvin é a relação de brincar que tem com a chuva. É o gesto de interpretação que a aluna dá ao texto, considerando o interlocutor.

\section{A PREVISIBILIDADE DAS LEITURAS}

Ao pensar os quatro textos escritos, há pontos de convergência entre eles e a proposta de leitura fornecida pela Análise de Discurso. Pontos importantes que podem lançar luzes à escola, em relação à forma como a leitura é enxergada por ela. Primeiro, a multiplicidade da leitura. Diante do objeto simbólico, houve diferentes gestos de interpretação. $\mathrm{O}$ mesmo texto atingiu de forma diversa os diferentes leitores. Cada aluno se ateve a um ponto na leitura. Isso porque o texto é dispersão do sujeito. $\mathrm{E}$ a unidade do texto não é plana. A impressão da unidade do texto e da planificação da leitura é causada pela ideologia (ORLANDI, 2008).

Falta à escola trabalhar essa multiplicidade de sentidos do objeto simbólico. Multiplicidade que advém do entrelaçamento do sujeito, da língua e da história, ponto nodal da Teoria do Discurso.

Em favor do sentido hegemônico, único, institucionalizado, a escola reprova o aluno quando ele resiste a esse sentido. Há um silenciamento de sentidos possíveis. A escola se põe como núcleo dos sentidos, sendo que "não há um centro (de sentidos) e suas margens, só há margens” (ORLANDI, 2008, p. 21).

Mas qual é o porquê de esses sentidos hegemônicos, selecionados, ocorrerem? A própria autora responde: "a história dos sentidos cristalizados é a história do jogo de poder da/na linguagem" (ORLANDI, 2008, p. 21). A dinâmica da sala de aula é assimétrica, o professor sustenta seus sentidos a partir de sua posição enquanto professor, não há abertura para outros sentidos possíveis. Orlandi (2011) caracteriza esse movimento como "discurso autoritário".

Uma proposta de saída desse círculo parece ser a aceitação do gesto de interpretação como a característica da assunção da autoria (ORLANDI, 2007, p. 97). 


\section{CONSIDERAÇões Finais}

A partir dos textos analisados, notamos que os alunos possuem diferentes relações com a língua(gem), que são resultados das diferentes formas de individuação pela língua e pela ideologia por que passam dentro do ambiente sócio-histórico em que se inserem. Os conhecimentos que demonstraram revelam a história que possuem com a leitura e a maneira como enxergam a leitura de quadrinhos. Sobretudo, há pouco contato com a atividade escrita e pouca leitura de textos autênticos.

Retomando o conceito de condições de produção - os sujeitos envolvidos em uma situação específica de produção de linguagem -, ressaltamos que os sujeitos-alunos aqui tratados estão em um processo de escolarização, portanto ainda com muito a aprender. Os gestos de interpretação dos alunos a partir da leitura de um texto autêntico existente no social revelaram que eles mobilizam uma memória de saber referente a uma concepção de língua "escolar", ou seja, um imaginário de língua que se toma como correta, tendo como interlocutor a escola, daí o uso intenso de conectivos, conjunções, elementos anafóricos, elipses e também a estrutura de uma frase embaixo da outra, na tentativa de "aumentar" o texto e torná-lo "escolarizável".

Porém, o que falta aos alunos em termos de conhecimentos não lhes prejudica na assunção da autoria, se um trabalho com a língua sujeita a falhas e equívocos for compreendido pela escola.

Acreditamos que o trabalho com textos autênticos, relevantes e valorizados socialmente, como as tirinhas, pode contribuir para melhorar a leitura escolar e fazer com que o aluno se posicione como autor do que escreve. Os textos autênticos já são legitimados institucionalmente e funcionam como modelos, pois são referências para aquilo que deve ser bem escrito; e é a oportunidade que o professor dá ao aluno para construir sua (do aluno) história de leitura (ORLANDI, 2008). Assim, eles retirariam a aula de língua portuguesa de um tratamento metalinguístico sem sujeito, o que é comum presenciar atualmente.

\section{REFERÊNCIAS}

FARACO, C. E.; MOURA, F. M. Gramática. São Paulo, SP: Ática, 1994.

FERREIRA, B. de H. Miniaurélio: o dicionário da língua portuguesa. $6^{a}$ ed. ver., Curitiba: Positivo, 2005. MARIANI, B. S. C. As leituras da/na Rocinha In: ORLANDI, E. P. (Org.). A leitura e os leitores. $2^{\text {a }}$ ed., Campinas, SP: Pontes, 2003. 
MILNER, J. C. O amor da língua. Campinas, SP: Editora da Unicamp, 2012.

ORLANDI, E. P. Análise de discurso. In: ORLANDI, E. P.; LAGAZZI, R. (Org.). Discurso e textualidade. Campinas: Pontes, 2006.

ORLANDI, E. P. Interpretação: autoria, leitura e efeitos do trabalho simbólico. Petrópolis: Vozes, 2007.

ORLANDI, E. P. Discurso e leitura. $8^{\mathrm{a}}$ ed., São Paulo: Cortez, 2008.

ORLANDI, E. P. A linguagem e seu funcionamento. Campinas: Pontes, 2011.

PÊCHEUX, M. O discurso: estrutura ou acontecimento. Campinas: Pontes, 1990.

PÊCHEUX, M. Ler o arquivo hoje. In: ORLANDI, E. (Org.). Gestos de leitura. Campinas: Editora da Unicamp, 2010.

\section{SOBRE O AUTOR}

Wagner Ernesto Jonas Franco é graduado em Letras pela Universidade do Vale do Sapucaí (UNIVÁS), especialista em Metodologia do Ensino em Língua Portuguesa e Estrangeira pelo Centro Universitário Internacional (UNINTER), Mestre em Ciências da Linguagem pela Universidade do Vale do Sapucaí (UNIVÁS) e doutorando em Linguística pela Universidade Estadual de Campinas (UNICAMP). É professor na Secretaria Municipal de Educação de Pouso Alegre.

E-mail: dominiumwagner@yahoo.com.br

Recebido em 20 de janeiro de 2015 e aprovado em 11 de novembro de 2015. 